\section{Summary}

Reports of eosinophilic granulomata in the gastro-intestinal tract have been appearing for over 25 years, but until recently the aetiology of these lesions has remained obscure. There is now evidence that at least some cases, especially those occurring in Western Europe, may be caused by the parasite Eustoma rotundatum, which commonly occurs in North Sea herrings, and may be ingested in uncooked or salted herring products, such as " roll-mops."

The cases of two patients with an eosinophilic granuloma of the small intestine are reported, one of whom is a fishmonger.

A series of 89 cases, with a total of 96 lesions, collected from the literature are reviewed. In about half the cases the lesion was in the stomach or pyloric antrum, and presented with gastric or pyloric symptoms. In a further third the small intestine was involved, causing intestinal obstruction.

The granuloma may occur in two forms, diffuse or localized. The histological features are described. Aetiology is discussed, and it is is suggested that eosinophilic granuloma represents a local allergic response to $E$. rotundatum, due to an immune state acquired by repeated reinfection with the parasite.

There is no specific treatment, but the prognosis is good, and conservative management is advocated rather than major resections whenever possible. Steroids have been used on several occasions.

We wish to thank Mr. F. d'Abreu, surgeon to the Westminster Hospital, and Mr. K. L. James, lately surgeon to the Gordon Hospital, for permission to publish reports of cases under their care.

\section{REFERENCES}

Barnett, L. A., and Kazmann, H. A. (1952). Amer. f. Surg., 84, 107.

Barrie, H. J., and Anderson, J. C. (1948). Lancet, 2, 1007.

Bauab, E. G. (1961). Pren. méd. argent., 48, 1311.

Booher, R. J., and Grant, R. N. (1951). Surgery, 30, 388.

Brunner, H. (1951). Oral Surg., 4, 623.

Cox, J. S. T. (1960). Brit. F. Surg., 48, 149.

Doniach, I., and McKeown, K. C. (1951). Ibid., 39, 247.
Fennel, E. A. (1952). Proc. Straub Clin. (Honolulu), 18, 69.

Ferrier, T., and Davis, N. (1957). Med. 7. Aust., 1, 789.

Feyrter, F. (1953). Arch. klin. Chir., 274, 320.

Fragala, G. (1942). Boll. Soc. med.-chir. Catania, 10, 339

Fragala, G. (1942). Boll. Soc. med.-chir. Catania, 10,

Helwig, E. B., and Ranier, A. (1953). Surg. Gynec. Obstet., 96, 355.

Herrera, J. M., and de la Guardia, J. (1948). Arch. Hosp. S. Tomás (Panamá), 3, 19.

Hollmotz, O., and Stepan, Z (1963). Cs. Rentgenol., 17, 65.

Judd, C. S., Civin, W. H., and McIlhany, M. L. (1955). Gastroenterology, 28, 453.

Kaijser, R. (1937). Arch. klin. Chir., 187, 351.

Kofler, E. (1952). Virchows. Arch. path. Anat., 321, 121.

Koneman, E. W., Sawyer, K. C., and Lubchenco, A. E. (1959). Arch. Surg., 78, 923.

Kuipers, F. C., VanThiel, P. H., and Roskam, E. T. (1960a). Ned. T. Geneesk., 104, 422.

- Rodenburg, W., Wielinga, W. J., and Roskam, R. T. (1960b). Lancet, 2, 1171 .

McCune, W. S., Gusack, M., and Newman, W. (1955). Ann. Surg., 142, 510.

Marek, S. (1954). Cas., Lék. česk., 93, 484.

Moloney, G. E. (1949). Lancet, 1, 412.

Nunes, M. A. (1950). Gaz. méd. port., 3, 751.

Orr, I. M., Miller, A. A., and Russell,' J.'Y. W. (1954). Postgrad. med. f., 30, 485 . Pardo, M.' V., and Rodriguez, T. I. (1952). Arch. Hosp. univ. (Habana),
4, 248 .

Pezzoli, A., and Reggiani, E. (1952). Arch. ital. Mal. Appar. dig., 18, 97.

Polayes, S. H., and Krieger, J. L. (1950). F. Amer. med. Ass., 143, 549.

Possner, M.; and Vanek, J. (1946). Cas. Lék. ¿esk., 85, 685.

Pound (1956). Personal communication: cited by Ferrier and Davis (1957).

Rigler, L. G., Blank, L., and Hebbel, R. (1956). Radiology, 66, 169.

Rodenburg, W., Wielinga, W. J. (1960). Ned. T. Geneesk., 104, 417.

Ruzic, J. P., Dorsey, J. M., Huber, H. L., and Armstrong, S. H. (1952). f. Amer. med. Ass., 149, 534.

de Santis, M. (1954). Polyclinico, Sez. prat., 61, 1521.

Schneider, H., and Dailey, M. E: (1948). Gastroenterology, 10, 727.

Sison, A. B. M., Dionisio, S. A., Silva, J. A., and Chavez, P. C. (1947). 7. Amer. med. Ass., 134, 1007.

Smith, M. J. (1956). Radiology, 66, 177.

Spencer, J. R., Comfort, M. W., and Dahlin, D. C. (1950). Gastroenterology, 15, 505 .

Steger, C., and Noto, L. (1953). Acta chir. patav., 9, 339.

Szechy, M., and Foldvari, G. (1962). Orv. Hetil., 103, 501.

Taccani, C.' (1952). Excerpta med. (Amst.), 1953, Sect. IX, No. 7650.

Toole, H. J., and Moschopoulos, A. N. (1959). Brit. F. Surg., 46, 445.

Unnewehr, F., and Ohrt, H. (1954). Zbl. Chir., 79, 91.

Urban, A., and Leńczyk, M. (1956). Pat. pol., 7, 307.

Vanek, J.' (1949). Amer. F. Path., 25, 397.

Virshup, M., and Mandelberg, A.' (1954). Ann. Surg., 139, 236

Voorhuis, F. J., and Eijlers, W. (1961). Ned. T. Geneesk., 105, 2542.

Zak, R. (1951). Lék. Listy, 6, 73.

\title{
Effect of Hypnosis on Allergic Skin Responses in Asthma and Hay-fever
}

\author{
LIONEL FRY,* M.B., B.SC., M.R.C.P. ; A. A. MASON,* M.B., в.S. ; R. S. BRUCE PEARSON,* D.M., F.R.C.P.
}

Brit. med. F., 1964, 1, 1145-1148

Hypnosis has been reported to be of therapeutic value in asthma (Asher, 1956 ; Stewart, 1957 ; Mason, 1960 ; Fry, 1957 ; Edwards, 1960 ; Maher-Loughnan et al., 1962) and in hay-fever (Mason, 1960).

The effect of hypnosis on the allergic skin responses has been investigated only on isolated subjects (Mason and Black, 1958) and recently on selected good hypnotic subjects (Black, 1963a, 1963b). It was considered important to investigate the effect of hypnosis on a direct allergic cutaneous response, and so help to elucidate the mechanism of action of the reported benefit offered by hypnosis to asthmatic and hay-fever patients.

\section{Material and Method}

Forty-seven subjects who had asthma and/or hay-fever and who had positive skin reactions to extracts of pollen or house- dust were included in the study. Three patients who could not be hypnotized were excluded.

The skin-testing was carried out by means of the prick-test. Four strengths of the extract were used on each arm. The first strength in the pollen cases contained 10,000 units in a preservative " tween 80 ," the second strength 1,000 units, and the third strength 100 units, and the fourth 10 units. In the case of house-dust extract the first strength was a commercial standard skin-test preparation, and the other strengths were dilutions of $1 / 10,1 / 100$, and $1 / 1000$ as with pollacine.

Each subject was tested on the anterior surface of both forearms with the four strengths of the allergen under test. Prior to hypnosis the tests were performed at 2, 7, 12, and $17 \mathrm{~cm}$. from the antecubital fossa, and after hypnosis at 4,9 ,

\footnotetext{
- From King's College Hospital, London.
} 
14 , and $19 \mathrm{~cm}$., so that any reduction in the size of reactions could not be attributed to the effect of local desensitization.

The investigation was divided into two parts. In the first part 18 subjects were randomly divided into two groups, A and B. In group A (the controls) the subjects were skin-tested on two occasions; the second tests were performed after an interval of two weeks. In group B (the hypnosis group) the nine subjects were also skin-tested twice; the interval between the tests was also two weeks. During the two-weeks period they were hypnotized on three occasions, and suggestions were given that their skin reactions would be abolished when they were tested again. To prevent the possibility that any difference in the results was due to a decrease in the strength of the extract after a period of time, the subjects were paired (one from each group) and the skin tests were performed at the same time on the two subjects. All tests were carried out by one of us (L.F.) who was not concerned with hypnotic treatment and who did not know which patients had been hypnotized.

In the second part of the investigation the 29 patients were divided randomly into three groups. The groups were termed $\mathrm{C}, \mathrm{D}$, and $\mathrm{E}$. The skin tests were performed in groups of three, one subject from each group.

All three groups were hypnotized. The suggestions made to the subjects under hypnosis differed in the three groups.

In group $C$ suggestion was given that the right arm would not react to skin tests when repeated; in group D suggestion was given that neither arm would react; and in group $E$ the subjects were hypnotized but no suggestion was made concerning their skin tests. None of the subjects had any direct suggestion made to them regarding their symptoms of asthma or hay-fever. All subjects were hypnotized on three occasions at weekly intervals, the skin tests being performed immediately before the first hypnotic session and immediately after the last hypnotic session as in groups A and B.

Again the skin tests were carried out by one of us (L.F.), who did not know what suggestions had been made to individual patients under hypnosis. In this way it was thought that unconscious subjective influences would not affect the result as might have happened had the hypnotist taken part in the measurement. Both weal and flare were measured. After 10 minutes the outlines of the weals and flares were demarcated by a ball-point pen. The maximum and minimum diameters were then measured and the mean was recorded.

Hypnosis was in each case carried out by one of us (A.A.M.), an experienced hypnotist.

The patient was considered to have been satisfactorily hypnotized under the following circumstances. The eyes closed in the manner commonly accepted as indicative of the hypnotic state, the so-called "cataleptic eyelid." There is progressive blinking, usually accompanied by lacrimation, which ends in a fluttering closure of the eyes. While in the trance state suggestions were made that the right hand would feel light and would float up into the air as though it were a balloon. All cases responded to this suggestion and were questioned after the trance regarding the nature of the response. All believed that the response was an involuntary one-that is, that the hand floated up under its own volition-and there was no positive or conscious desire to assist the hypnotist by lifting it.

The method of hypnosis used was invariably a simple technique of progressive relaxation with suggestions of sleepiness, tiredness, and eye-closure. Approximately 10 minutes was spent on each patient, and in three cases this was repeated on a second occasion because the first failed to produce the desired response. These three also failed on the second attempt and were excluded from the trial; all other patients responded on the first occasion. In only one patient had a previous attempt at hypnosis been made, and this was for psoriasis. On that occasion hypnosis was not achieved, but in this trial it was successfully attained at the first attempt. When the hypnotic state was thought to have been reached, the following suggestion was made to the subjects in groups B, D, and the right arm of those in group $C$ : "When you come back and are tested again you will not respond as you did previously, with swelling, redness, burning, and itching ; there will be no reaction at all, no redness, no swelling, no itching, or burning." This exhortation was repeated several times; the trance was terminated by telling the patient that he would wake after the hypnotist had counted ten.

\section{Results}

Table I shows the mean difference in the size of the weals on the two occasions when the subjects in groups A and B were skin-tested. It can be seen that at the two lower strengths of allergen there is a highly significant decrease $(P<0.01)$ in the size of the weal after hypnosis, but this is not evident in the control group. Three subjects (out of the nine) who had reacted to all four strengths of extract prior to hypnosis failed to react after hypnosis to the two lowest strengths of allergen, but in no case was complete abolition of skin sensitivity achieved to all four strengths. Fig. 1 represents diagrammatically the sum of the change in the size of the weal at all four strengths for each individual in the control group, and Fig. 2 for the hypnosis group. All subjects showed a decrease at all four strengths in the hypnosis group. The flare showed a similar trend.

\begin{tabular}{|c|c|c|c|c|}
\hline \multirow{3}{*}{$\begin{array}{l}\text { Strength } \\
\text { of } \\
\text { Solution }\end{array}$} & \multicolumn{4}{|c|}{ Mean Size of Weals in Right and Left Arms Combined } \\
\hline & \multicolumn{2}{|c|}{ Group A } & \multicolumn{2}{|c|}{ Group B } \\
\hline & First & $\begin{array}{l}\text { Mean Decrease } \\
\text { at Second Test }\end{array}$ & First & $\begin{array}{l}\text { Mean Decrease } \\
\text { After Hypnosis }\end{array}$ \\
\hline $\begin{array}{l}1 \\
2 \\
3 \\
4\end{array}$ & $\begin{array}{r}16 \cdot 4 \\
10 \cdot 8 \\
8 \cdot 2 \\
4 \cdot 0\end{array}$ & $\begin{array}{l}1.9( \pm 1.00) \\
0.1( \pm 0.830) \\
1.0( \pm 1.430) \\
0.9(+0.788)\end{array}$ & $\begin{array}{r}18 \cdot 2 \\
12 \cdot 0 \\
9 \cdot 6 \\
7 \cdot 2\end{array}$ & $\begin{array}{l}1.9( \pm 1.295) \\
0.2( \pm 0.563) \\
4.9( \pm 0.506) \\
3.9( \pm 0.876)\end{array}$ \\
\hline
\end{tabular}

Table II shows the mean decrease in the size of the weals in groups $C, D$, and $E$ at each strength of allergen, and the average decrease in size for all four strengths. Although a decrease can be seen in all three groups, there is no significant difference between them. There is a decrease in the size of the weals at all four strengths, but, as with group B, a proportionately larger decrease at the lower strengths. In group $\mathrm{C}$ there was no significant difference between the size of the reactions on the two arms after hypnosis (Table III).

TABLE II.-Combined Size of Weals in Right and Left Arms and the Mean Decrease in Size of Weals After Hypnosis, in Groups $C, D$ and $E$. Measurements in $\mathrm{mm}$.

\begin{tabular}{|c|c|c|c|c|c|c|}
\hline \multirow{3}{*}{$\begin{array}{l}\text { Strength } \\
\text { of } \\
\text { Solution }\end{array}$} & \multicolumn{6}{|c|}{ Mean Size of Weals in Right and Left Arms Combined. } \\
\hline & \multicolumn{2}{|c|}{ Group C } & \multicolumn{2}{|c|}{ Group D } & \multicolumn{2}{|c|}{ Group E } \\
\hline & First & $\begin{array}{c}\text { Mean } \\
\text { Decrease }\end{array}$ & First & $\begin{array}{c}\text { Mean } \\
\text { Decrease }\end{array}$ & First & $\begin{array}{c}\text { Mean } \\
\text { Decrease }\end{array}$ \\
\hline $\begin{array}{l}1 \\
2 \\
3 \\
4\end{array}$ & $\begin{array}{r}17.2 \\
11.4 \\
8.0 \\
4.9\end{array}$ & $\begin{array}{l}2.0 \\
1.8 \\
5.0 \\
3.0\end{array}$ & $\begin{array}{r}18.0 \\
17.1 \\
9.2 \\
4.0\end{array}$ & $\begin{array}{l}1.6 \\
2.4 \\
1.2 \\
2.0\end{array}$ & $\begin{array}{r}16.8 \\
11.9 \\
8.1 \\
4.9\end{array}$ & $\begin{array}{l}2.4 \\
3.6 \\
2.2 \\
3.0\end{array}$ \\
\hline Average & & $2 \cdot 70( \pm 1 \cdot 02)$ & & $1 \cdot 72( \pm 1 \cdot 00)$ & & $2 \cdot 28( \pm 1 \cdot 02)$ \\
\hline
\end{tabular}

TABLE III-Group C. Comparison of Average Decrease in Size of Weals in Right and Left Arms for Each Strength of Extract. After Specific

\begin{tabular}{|c|c|c|c|c|}
\hline \multirow{3}{*}{$\begin{array}{l}\text { Strength } \\
\text { of } \\
\text { Solution }\end{array}$} & \multicolumn{4}{|c|}{ Average Size of Weal } \\
\hline & \multicolumn{2}{|c|}{ Right } & \multicolumn{2}{|c|}{ Left } \\
\hline & First & Mean Decrease & First & Mean Decrease \\
\hline $\begin{array}{l}1 \\
2 \\
3 \\
4\end{array}$ & $\begin{array}{l}9 \cdot 1 \\
5 \cdot 4 \\
4 \cdot 3 \\
2 \cdot 3\end{array}$ & $\begin{array}{l}1.2 \\
0.7 \\
1.0 \\
0.3\end{array}$ & $\begin{array}{l}7 \cdot 8 \\
5 \cdot 8 \\
4 \cdot 3 \\
2 \cdot 6\end{array}$ & $\begin{array}{l}0.5 \\
0.7 \\
1.6 \\
1.4\end{array}$ \\
\hline
\end{tabular}


It should be pointed out that the results in the tables are averages for the whole group, and when looked at individually not all patients did in fact show decreases. Seven patientsthree from group $C$, one from group $D$, and three from group $E$ -showed an increase in the size of the weals after hypnosis. It also should be stressed that if a reduction occurs at one strength then it tends to occur at all strengths in the same

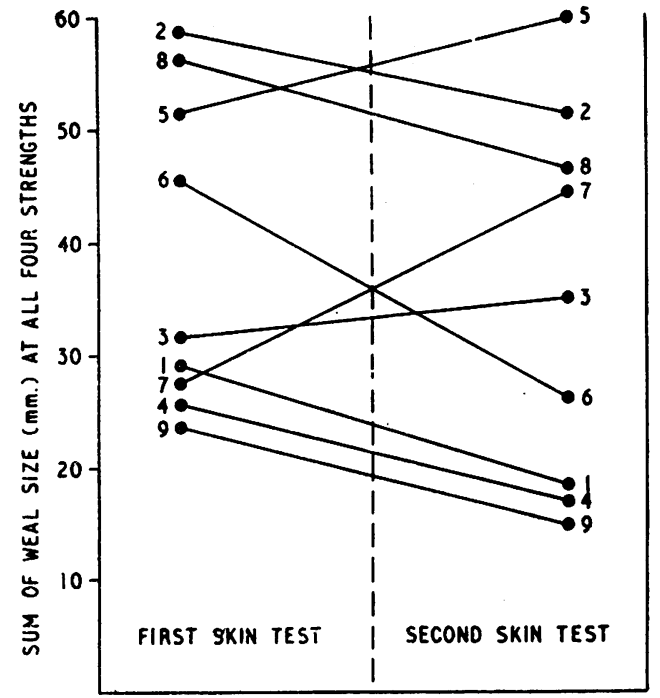

Fig. 1.-Group A. Control group.

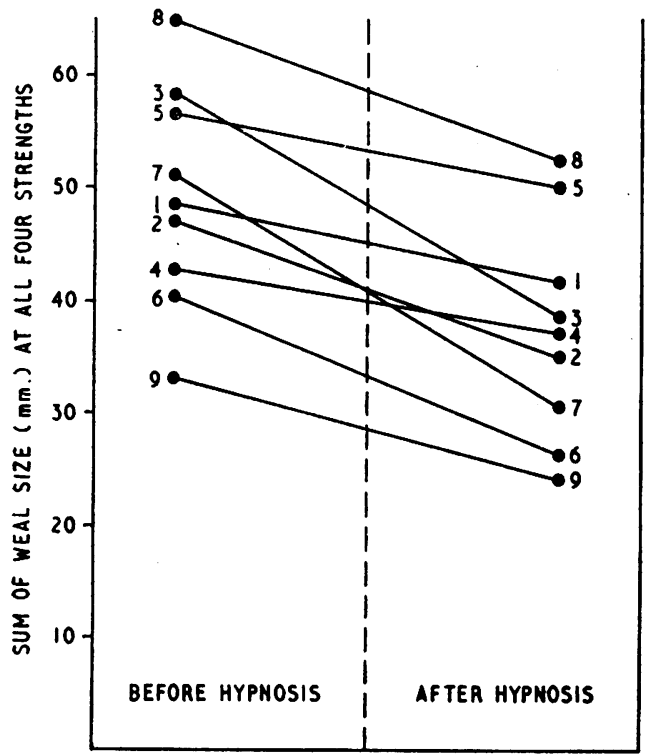

FIG. 2.-Group B. Hypnosis group.

subject. Figs. 3, 4, and 5 represent the change in the size of the weal after hypnosis in each individual. It can be seen that there is considerable variation among the subjects, even if the majority do show a decrease in the size of the weals. In all cases the flares showed a trend similar to that of the weals.

\section{Discussion}

These investigations on the effect of hypnosis on skin sensitivity were undertaken because it was thought that a definite and objective result could be obtained and that it might help in understanding the effect of hypnosis on allergic mechanisms.

The patients to be treated were in the first instance selected by one of us (R.S.B.P.) purely on the grounds of skin sensitivity and willingness to take part in the experiment. As already stated, only one had been previously subjected to hypnosis, and on that occasion unsuccessfully. For this reason the subjects differ from those investigated by Mason and Black (1958), Black (1963a, 1963b), and Black et al. (1963), who were selected for their exceptional capacity to achieve a deep-trance state. Other important differences with previously published results (Mason and Black, 1958; Black, 1963a ; Black et al., 1963) were that hypnosis was carried out on only three occasions in each subject and that no attempt at hypnoanalysis or indeed any form of psychiatric assessment was made. There was no suggestion of therapeutic gain, either before or during hypnosis, but it was initially explained to patients that the effect of

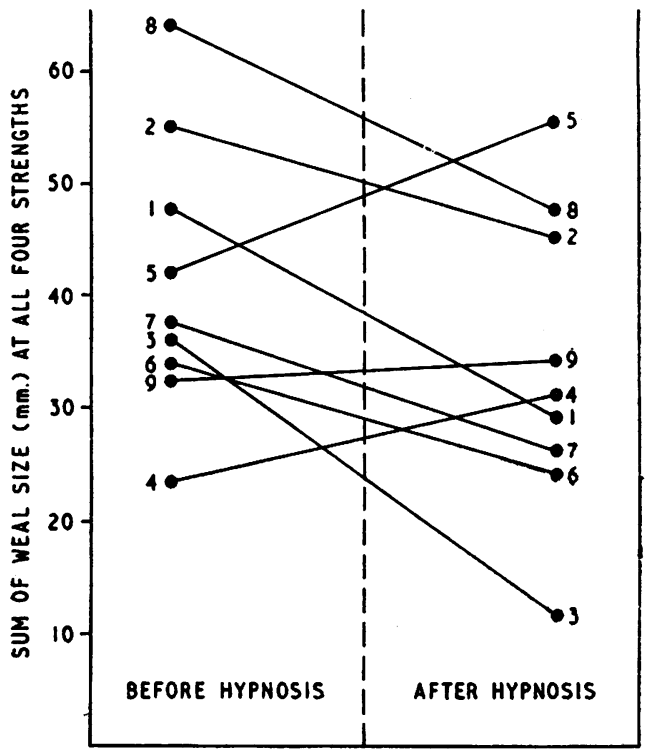

Fig. 3.-Group C. Suggestion directed to only one arm.

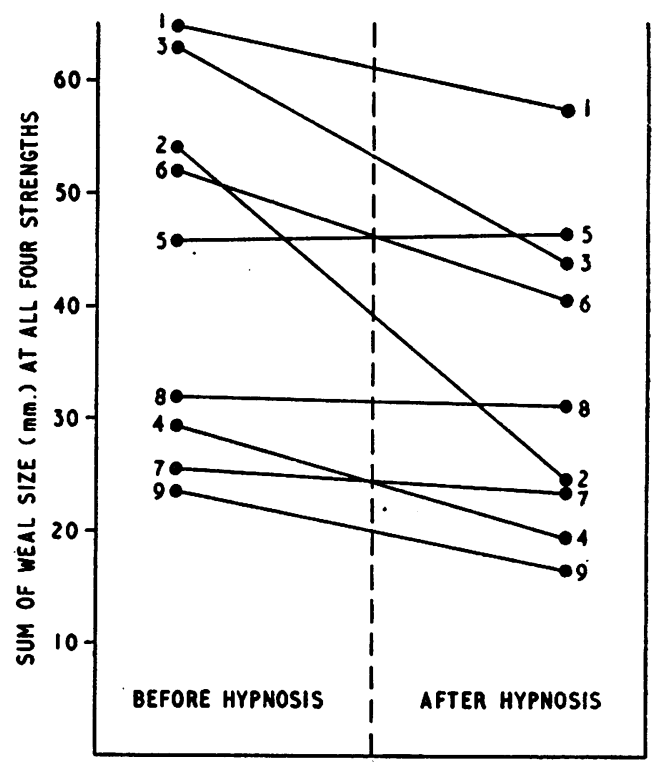

FIG. 4.-Group D. Suggestion directed to both

hypnosis on their skin reactions might indicate their suitability for further hypnotic treatment. In fact, all patients included in the trial were subsequently given hypnotic treatment for their asthma or hay-fever.

In the present trial a moderate reduction in skin sensitivity was demonstrated as a result of hypnotic suggestion, and three of the nine patients in the hypnotized group B responded more strikingly than the remaining six. It is believed that similar 
results would be achieved by simple hypnotic suggestion in other comparable unselected groups. This is not incompatible with the findings of Mason and Black (1958) and Black (1963a), who experimented under different conditions.

In the second part of the experiment an attempt was made to investigate the mechanism whereby hypnosis achieved its effect. Under the conditions of the investigation two questions were posed. (1) Is the effect of suggestion under hypnosis important, or does it depend on a preconceived view held by the patient? (2) Can suggestions made under hypnosis cause

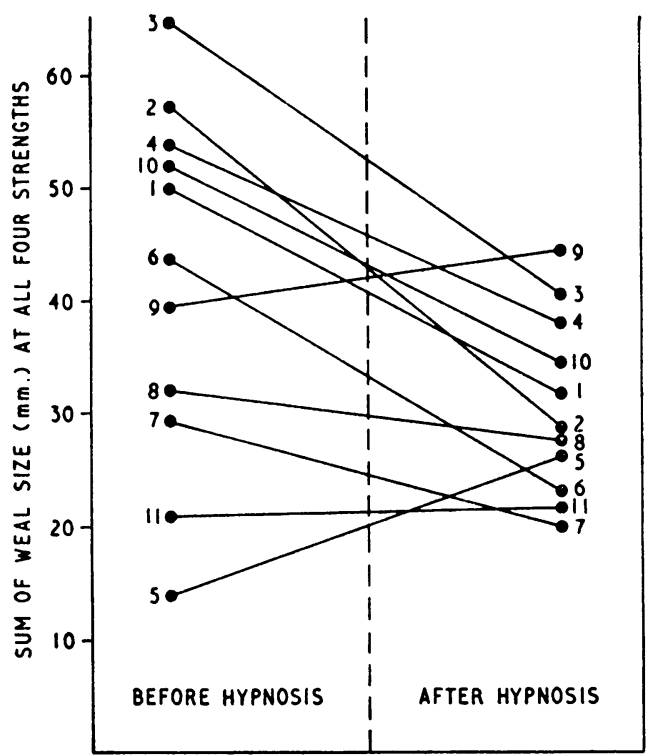

FIG. 5.-Group E. Hypnotized, but no suggestion given regarding skin tests.

the patient to react differently in the two arms ? In fact, in group C (those in whom it was suggested that the right arm would fail to react) no difference in the size of reactions in the two arms was observed, although there was a moderate average reduction in the size of reactions in the group as a whole. It therefore appeared that in this group any hypnotic effect directed to one arm also involved the other arm.

It is of interest that the mere act of hypnosis without any specific suggestion appeared to produce a reduction in skin reactivity comparable to that achieved by specific suggestion under hypnosis. The patients in this group would certainly have been aware before treatment that the effect of hypnosis was to be measured by changes in the size of skin reactions and may have inferred that there was some therapeutic significance. For one reason or another this group behaved differently from group $\mathrm{A}$, in which no suggestions regarding skin tests were made and in which hypnosis was not undertaken.

One may conclude that hypnosis carried out on three occasions in a group of patients selected only for the presence of skin sensitivity and willingness to co-operate is capable of bringing about a quantitative reduction in skin reactivity. Dramatic reduction of sensitivity in the higher strengths was not seen in any of the patients treated, and it is probable that striking results of this type can only rarely be achieved in individuals. It also is apparent from these simple experiments that there is a quite appreciable difference amongst individuals to similar hypnotic suggestions.

\section{Summary}

Forty-seven subjects with known skin sensitivity to pollen and/or house-dust were divided into five groups and tested with four strengths of allergen. The prick-test method was employed.

In the first part of the investigation a group of unhypnotized subjects were compared with a group who had suggestions made under hypnosis that their skin reactions to the allergen would not occur when tested a second time. A significant diminution in the size of the weal was obtained in the hypnosis group at the lower two strengths of allergen.

In the second part of the investigation the subjects were divided into three groups. All were hypnotized, no suggestions regarding skin reactions were given to one group, the second group were given suggestions that only on one arm would the skin reactions be less or not recur, and in the third group the suggestion was made about the reactions on both arms. There was found to be a similar decrease in the response to prick-tests after hypnosis in all three groups.

We should like to thank Professor Denis Hill for his advice. A.A.M. wishes to acknowledge a grant from the Asthma Research Council, and L.F. a grant from the Research Committee, King's College Hospital. We also thank Dr. John Fry for asking subjects in his practice to take part in the trial.

\section{REFERENCES}

Asher, R. (1956). Brit. med. F., 1, 309.

Black, S. (1963a). Ibid., 1, 925

- (1963b). Ibid., 1, 990.

- Humphrey, J. H., and Niven, J. S. F. (1963). Ibid., 1, 1649.

Edwards, G. (1960). Ibid., 2, 492.

Fry, A. (1957). Ibid., 1, 1323.

Maher-Loughnan, G. P., Macdonald, N., Mason, A. A., and Fry, L. (1962). Ibid., 2, 371.

Mason, A. A. (1960). Acta allerg. (Kbh.), 15, Suppl. No. 7, p. 332.

- and Black, S. (1958). Lancet, 1, 877.

Stewart, H. (1957). Brit. med. F., 1, 1320. 